\title{
Health of the territory's population: the main factors and trends in reducing their impact
}

\author{
Vladimir Kurdyukov ${ }^{1 *}$, Sergey Agafonov ${ }^{1}$, Dmitriy Zhikharev ${ }^{1}$, and Sergey Kanurny ${ }^{1}$ \\ ${ }^{1}$ Don State Technical University, 1, sq. Gagarina, 344003, Rostov-on-Don, Russia
}

\begin{abstract}
An analysis of the situation in one of the regions of the Russian Federation was carried out on the basis of the official information available. Mortality in the region has been declining for several years until 2020. However, the trend continued in the largest city of the region. Comparison of the estimated pollutant emission masses in Rostov-on-Don with the maximum permissible load on the ecosystem shows their exceedance by the main pollutants by a tenfold, which indicates the importance of the environmental factor for public health. It was noted that under restrictions associated with the outbreak of infectious diseases, the environmental factor for the territory had declined and other factors were likely to increase. Different approaches can offer a range of tools, which implies the need for scientific discussion based on current developments. Refusal to explore alternatives creates moral risks for the informed party. The experience of 2020 allowed accumulating competencies and working out actions for the formation and implementation of a strategy of behaviour in the future. One of the dominant factors contributing to the improvement of public health is the preservation and strengthening of immunity. Common effective means of increasing immunity in urban environments are considered.
\end{abstract}

\section{Introduction}

The sustainable development goals now recognize the urgent need to improve territorial health and environmental sustainability [1]. In general, common, biological, environmental and socio-economic factors affect health and well-being. The dynamic interaction of all influencing factors that determine the outcome and well-being of human health needs to be addressed in an integrated manner [2].

Many scientists are investigating in detail certain aspects of influencing factors. For example, Hymie Anisman and others [3] assume that the nature of lifestyle - nutrition, physical activity, sleep - affects health. This can have a significant impact on many preventable diseases, including psychological disorders such as anxiety and depression, and many physical disorders, especially those associated with the inflammatory component. Stressors also affect neurobiological and immune processes, thereby affecting the development and course of diseases.

\footnotetext{
* Corresponding author: kurdvn@mail.ru
} 
Environmental impacts or environmental risk factors are of particular importance to the health of population. For example, air pollution tended to be the highest environmental risk to public health, with the corresponding number of deaths in Athens, Barcelona and London ranging from 800 to 2,300 per year. The number of road accidents and related deaths was the lowest in the past year compared to the previous ones [4]. The paper also examines health benefits of urban green spaces by calculating impact on the mortality of population living in high-cover areas. Results in Athens showed a 26 per 100,000 reduction in all-cause mortality among the population benefiting from local greenery. Based on the analysis, recommendations for potential interventions that can be implemented to reduce environmental health risks in the European metropolitan areas covered by this study were developed.

The World Health Organization (WHO) estimates that noise accounts for 1 million years of healthy life lost annually in Western Europe due to increased cases of hypertension, heart failure, myocardial infarction and stroke. More severe health effects have been reported from air pollution (e.g., PM 2.5) causing up to 800,000 additional deaths per year in Europe [5].

The project «Aphekom» also carried out studies on the effects of air pollution in Europe, assessing the health and monetary benefits of reducing short- and long-term exposure to particulate matter (PM) and ozone in 25 European cities. The results showed that compliance with the WHO recommendations for a $10 \mathrm{ug} / \mathrm{m} 3$ level of acceptable pollution per year would add up to an average of 22 months of life expectancy for a total of up to 30 years, depending on the city, which corresponds to a total of 19,000 postponed deaths. The corresponding monetary gain will be about 31 billion euros per year [6]. It is important to note that the problem of PM 2.5 is not unique to European cities, but relates to many others around the world. India, for example, has an annual average of PM $2.5=40 \mathrm{ug} / \mathrm{m} 3$, therefore, work is under way to achieve the National Clean Air Programme policy (30\% reduction) [7]. In South Africa, 28,000 premature deaths can be prevented if the stricter WHO guidelines for annual PM 2.5 are met, equivalent to $6 \%$ of all deaths in South Africa due to PM 2.5 [8]. Research by Chinese scientists shows that carbon emissions have a long-term adverse impact on the residents' health - a $1 \%$ increase in carbon emissions adds $0.298 \%$ more outpatients and $0.162 \%$ more inpatients [9].

A modern approach to monitoring health effects of vehicle emissions should take into account the variability of vehicle emissions due to variability in temperature, road peculiarities and road behaviour; seasonal variability of concentration - response coefficients; demographic variability at the fine spatial scale; uncertainty in the accuracy of the air quality model; uncertainty in concentration-response ratios [10]. To reduce the impact on public health, a study was conducted by scientists from Stockholm to determine the efficiency of switching from cars to bicycles for trips of up to 30 minutes. The calculation result showed a reduction in the average population exposure of about $7 \%$ [11].

In addition, changing climatic conditions are an important factor. Cities have a significant impact on greenhouse gas emissions, since most of the transport, industry, trade and more than $50 \%$ of the world's population is concentrated in urban areas [12]. Achieving the climate targets agreed at the 2015 Paris Climate Conference requires rapid and large-scale reductions in greenhouse gas emissions. There will be significant health, livelihood and ecosystem risks associated with large-scale mitigation, but new opportunities may also emerge [13].

In addition to these factors, the health effects of hazardous wastes are important. Most studies on the relationship between hazardous waste and public health fail to establish mechanistic links between environmental exposure and, as a result, disease, resulting in inefficient waste management options. Therefore, they should not be considered in isolation, but rather as a vector of human exposure over time [14]. 
Significant improvements in public health can be achieved in the coming decades by reducing air pollution. To better understand the potential of emission policies, studies are needed that assess possible future health impacts under alternative assumptions of future emissions and climate at different spatial scales [15]. Air pollution is one of the leading causes of mortality and morbidity worldwide. The analysis of factors for territory and the improvement of air quality are important for achieving sustainable development goals in health (goal 3) and in cities (goal 11), and is therefore an urgent scientific challenge. We will analyse the situation in the territory on the basis of the official information available. We will also formulate the main recommendations and directions for reducing negative factors and health effects, which are consistent with different concepts.

\section{Methods}

An analysis of works on factors affecting public health made it possible to draw a number of conclusions and set objectives for the consideration of the object of research, which is one of the regions of Russia, the Rostov region.

Health and quality of life are among the main indicators of well-being in the territory. The environmental characteristics of any region and the level of scientific and technological progress largely determine the health status of population. Various combinations of abiotic factors affect health and determine the distribution of species across territories. Changes in human habitats caused by various factors, usually of anthropogenic origin, have led to environmental deviations. The most significant negative impact on the environment of urban areas in terms of health effects is the emission of pollutants into the air.

An analysis of literary sources revealed the main factors influencing health of the territory's population. In 1994 (in the Federal concept «Protection of health and population»), the ratio was determined for our country as follows:

genetic factors - $15-20 \%$;

environmental health - 20-25\%;

health care - $10-15 \%$;

living conditions and way of life - 50-55\%.

The contribution of individual factors of different nature to health indicators depends on the age, gender and individual typological characteristics of a person. The significance of these factors can vary considerably for different territories and seasons and largely depends on the created and existing conditions.

To assess the situation in the territory, the analysis of statistical data characterizing the main factors affecting health and the causes of death was carried out. The baseline data were mass emissions and concentrations of pollutants in the territory. The maximum permissible concentrations of pollutants, the maximum permissible load on the ecosystem (for comparison with actual emissions using the model [16]), and mortality of the territory's population were used as indicators. The importance of factors affecting the health of population is also examined by the structure of causes of death. From the analysis of the situation in the territory, we will consider ways of reducing the impact of negative factors.

The interdisciplinary nature of the issues makes it difficult to identify and to assess all the factors with precision. At the same time, the evolution of indicators and the identification of trends will allow developing general recommendations for the formation of behavioural strategies. Information constraints and the dominant management decision-making methodology (e.g., in environmental protection [17]) make it difficult to compare all alternatives qualitatively and adequately. 
Analysis and comparison of various concepts of disease manifestation and health improvement, such as concepts of A. Ukhtomsky (1875 -1942), A. Speransky (1887 - 1961), modern scientific achievements (F. Burnet, P. Medawar, G. Edelman, G. Köhler, C. Milstein, S. Tonegawa and others) will allow more informed management decisions to be made. A comparison of general recommendations and the characteristics of the situation in the territory would reveal behavioural errors that lead to negative consequences and stimulate them. An institutional analysis of the situation will also reveal some reasons for deviations from the best behaviour strategy.

\section{Results}

Consumer attitudes towards the use of natural resources, air, soil and land pollution, urbanization and the growing needs of the population negatively affect the overall environmental situation. Industrial waste, hazardous chemicals enter the human body along with food, water and air and undermine public health of Russian citizens.

More than a hundred cities in the Russian Federation are in a high-pollution zone and only 15 per cent of Russians live in favourable environmental conditions. Inefficient farming has also negatively impacted the soil, where pesticide residues are constantly accumulating. The unfavorable ecological situation is aggravated by a huge number of natural and man-made disasters that have occurred in our country over the past decades.

So, according to The Russian Federal State Statistics Service (Rosstat), the most significant impacts of negative environmental factors were observed in Irkutsk, Kemerovo, Murmansk, Chelyabinsk region, Krasnoyarsk territory, Nenets Autonomous Area and Khanty-Mansi Autonomous Area.

Related risk factors that have a negative impact on the health of the population in the Russian Federation are the crisis in the health care and social protection system, namely: low qualifications of medical workers, shortage of medicines, low salaries, insufficient physical activity, poor nutrition, neglection of non-communicable diseases, etc. [18].

The ecological situation in the Rostov region is currently characterized as unfavourable; the level of environmental pollution is high. The largest settlement in the region, Rostov-on-Don, is a city with a high index of atmospheric air pollution. Its quality does not meet the established hygienic standards for a long time, which poses an increased environmental risk to public health. Novocherkassk, Volgodonsk, and Azov are periodically included in the list of Russian cities with a high index of atmospheric air pollution, along with Rostov-on-Don,

Road transport in Rostov-on-Don accounts for $90-95 \%$ of total emissions. The main pollutants in the city atmosphere are formaldehyde, nitrogen dioxide, benzo(a)pyrene and dust (figure 1). Concentrations of these substances exceeding the maximum permissible concentration cause inflammation of skin, respiratory organs and mucous membranes of eyes and throat, have a negative effect on the reproductive system and increase the incidence of malignant neoplasms among population. Some of these diseases are tending to increase; the rates of most of them exceed those on average in Russia (figure 2).

In addition to emissions from road transport, emissions from the abrasion of road pavements and parts of vehicles, as well as from heating of tires during operation, have a significant impact on air pollution. At the same time, accurate estimation of particulate matter emissions from road abrasion requires either roadside surveys (to determine wear), or additional [19] studies of abrasion intensity, depending on the types and brands of tyres and vehicle mileage, as well as relevant baseline data. 


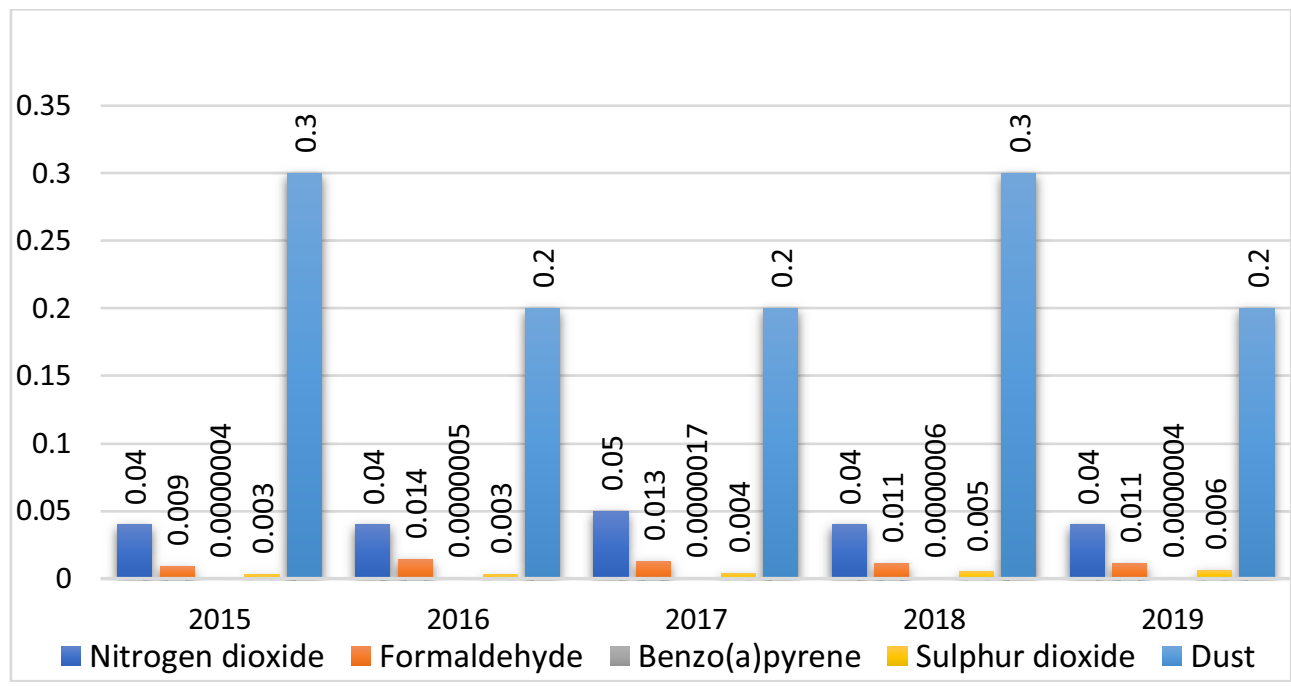

Fig. 1. Changes in air pollution by various impurities in 2015-2019 in Rostov-on-Don, $\mathrm{mg} / \mathrm{m}^{3}$ Source: https://xn--dlahaoghbejbc5k.xn--plai/projects/19/.

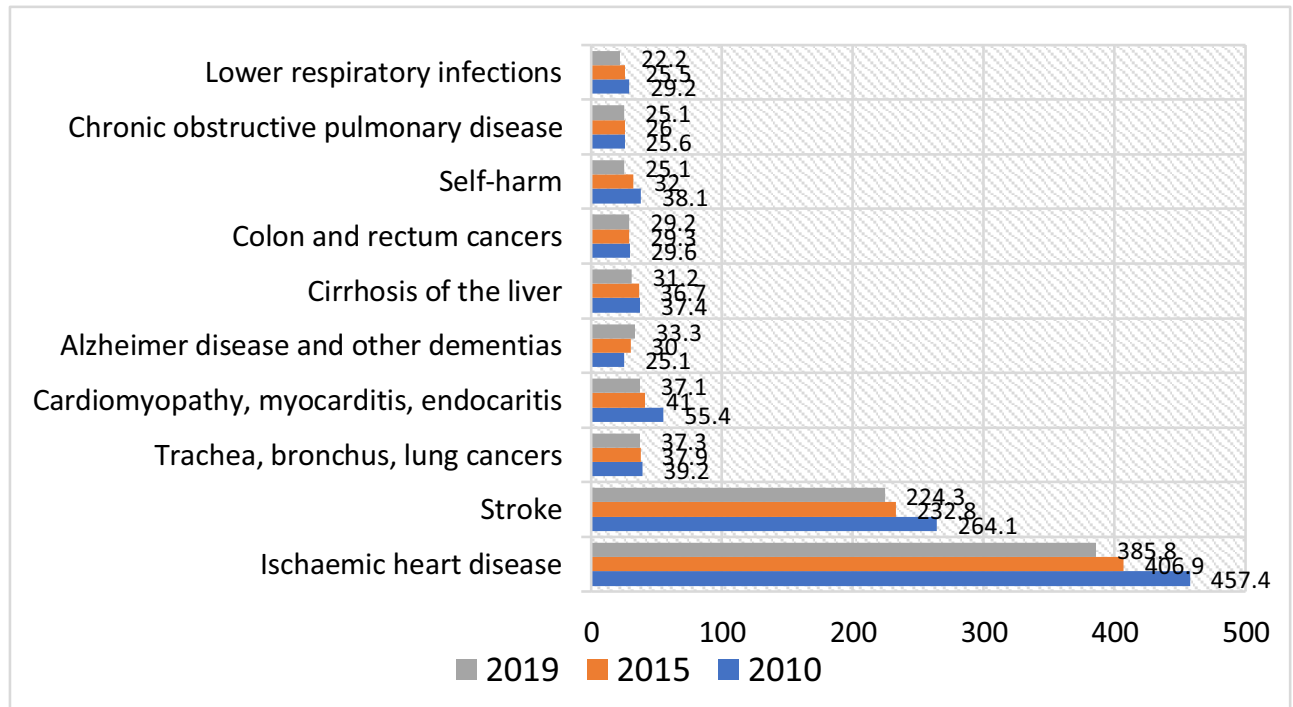

Fig. 2. Dynamics of the main causes of death in the Russian Federation for 2010-2019, deaths per 100.000 population. Source: https://www.who.int/data/gho/data/themes/ mortality-and-global-healthestimates/ghe-leading-causes-of-death.

Given the location of numerous environmental pollution sources on the territory of Rostovon-Don, the high density of population and urban development, the environmental factor can have an increased impact on public health.

Emissions of pollutants into the air in the region have been declining in recent years (Figure 3). 


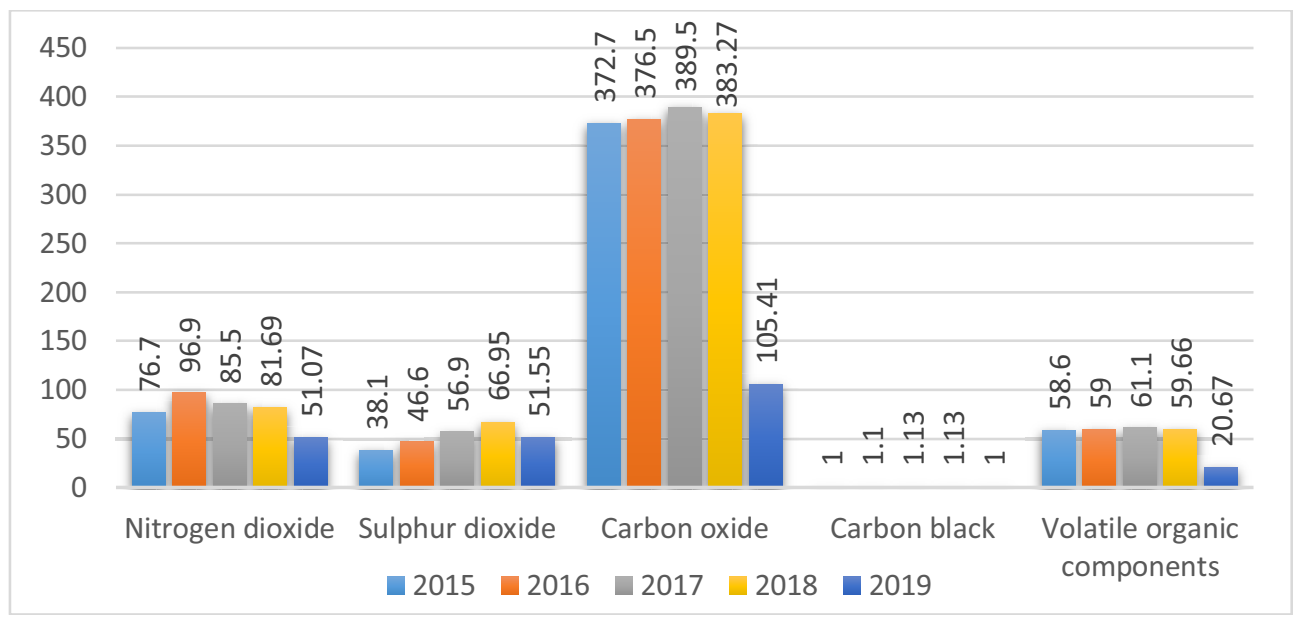

Fig. 3. Dynamics of the main indicators of pollutant emissions into the air of the Rostov region by mobile and stationary sources for 2015-2019, thousand tons. Source: https://xn--dlahaoghbejbc5k.xn-plai/projects/19/.

Comparison according to the model [16] of the calculated masses of pollutant emissions in Rostov-on-Don [19] and the maximum permissible load on the ecosystem [20] shows their exceedance by the main pollutants by tens of times, which points to the importance of the environmental factor for public health.

The mortality rate in the Rostov region has been declining for several years. In 2020, it increased by $14.7 \%$ (figure 4 ). At the same time, the mortality rate in Rostov-on-Don, the largest city in the region, fell by $3.7 \%$ (figure 5). The lack of official data on causes of death for 2020 complicates a full analysis. However, it can be noted that the territory has experienced a decline in environmental factors owing to economic constraints associated with the outbreak of infectious diseases (which does not guarantee that it will be reduced for individuals under restrictive conditions of movements between their places of residence) and the likely growth of other factors.

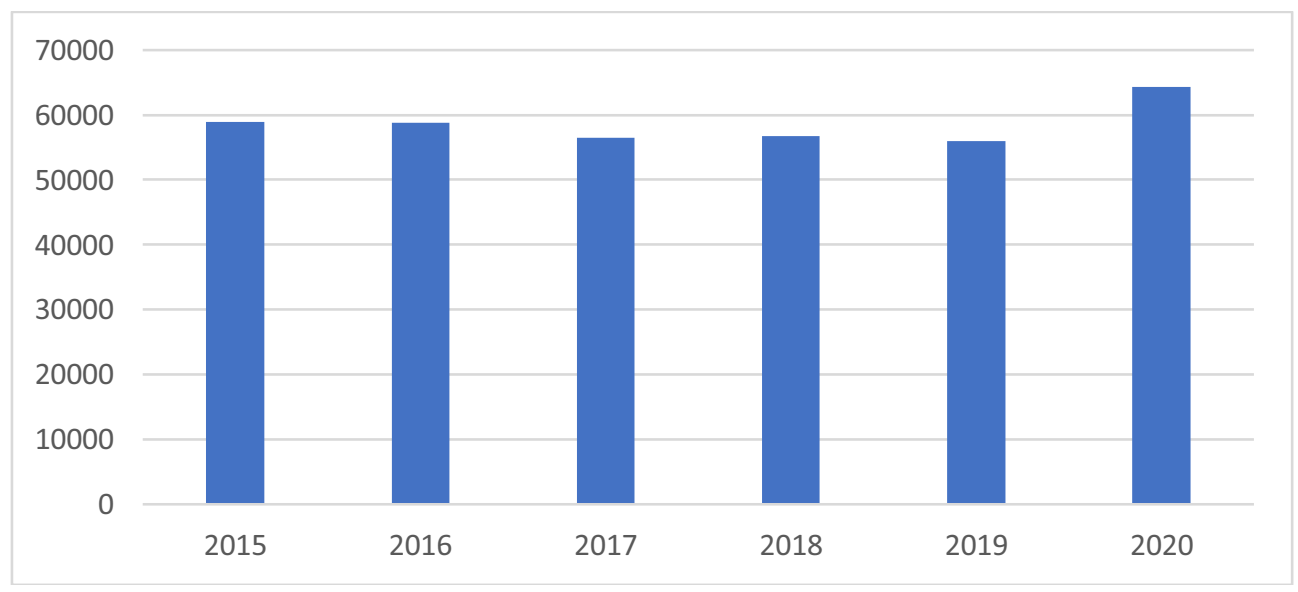

Fig. 4. Dynamics of the mortality rate in the Rostov region for 2015-2020, people. Source: https://www.donland.ru/result-report/854/. 


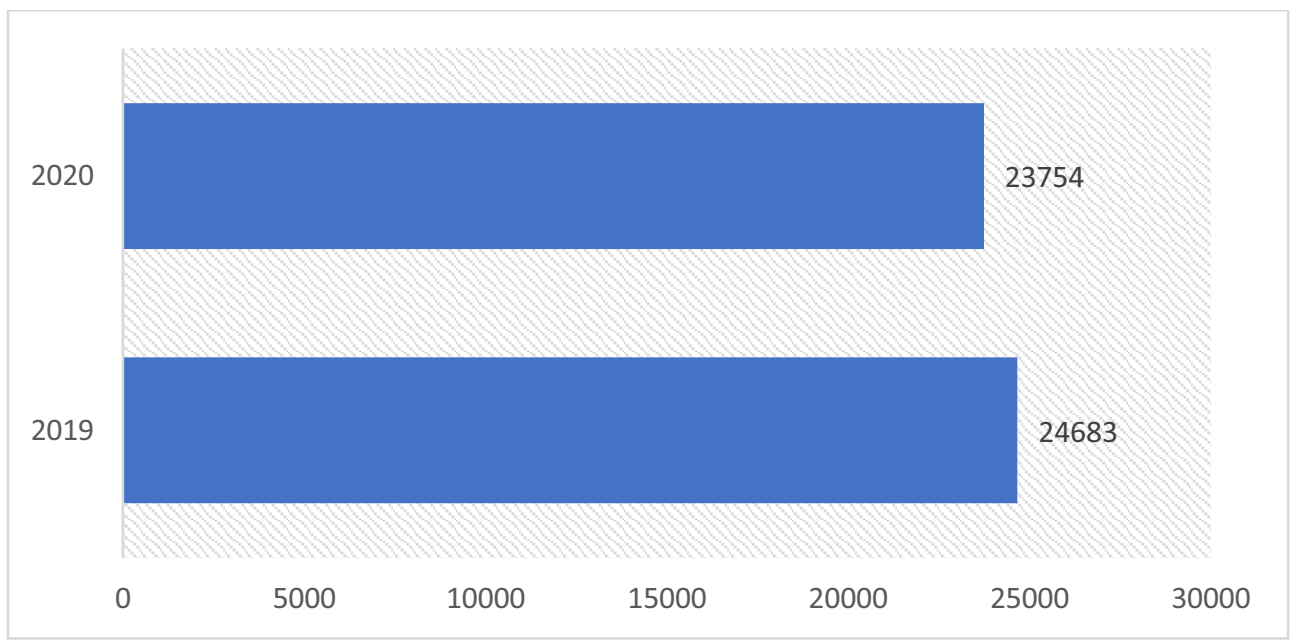

Fig. 5. Dynamics of the mortality rate in Rostov-on-Don for 2019-2020, people. Source: https://rosinfostat.ru/naselenie-rostova-na-donu/.

Analysis of the dynamics of mortality by the main categories of death causes in the Rostov region for 2016-2019 (figure 6) shows an increase in the structure of causes of death of neoplasms and respiratory diseases. However, the complexity of measuring environmental change under constraints, identifying the main and concomitant causes of mortality, can distort the situation significantly, both for assessment and for effective decision-making within the territory. Data for 2020 will provide a more complete picture.

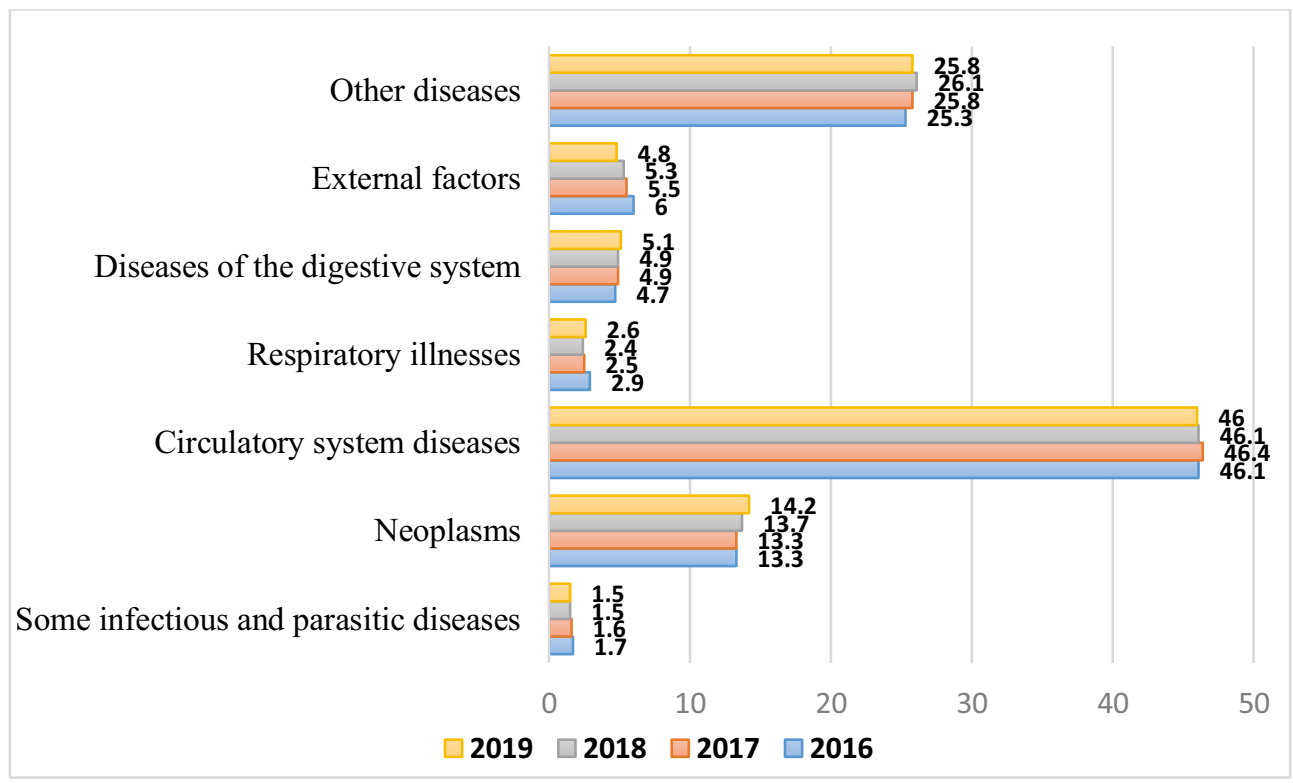

Fig. 6. Dynamics of mortality by the main classes of death causes in the Rostov region for 2016-2019, $\%$ Source:https://rostov.gks.ru/storage/mediabank/lW7gcIiG/\%DO\%B5\%DO\%

B6\%D0\%B5\%D0\%B3\%D0\%BE\%D0\%B4\%D0\%BD\%D0\%B8\%D0\%BA2019.pdf. 
Analysis of statistical data and identification of the main causes of the adverse effects on the health of the population of the territory make it possible to identify the main directions of reducing factors. The shortcomings and limitations of data on the situation in 2020 make full analysis difficult. At the same time, the diversity of negative factors implies an adequate strategy that includes a mix of various methods.

This current situation calls for new resources to deal with the problems of preserving the environment and improving public health, the reduction of the externalities of the territory's road transport system (for example, through its effective internalization [21]), the introduction of resource-efficient technologies in all sectors of production, the use of alternative energy sources, ensuring the restoration of the stability of already damaged ecosystems and their preservation in the future.

The selection of the most effective solutions involves analysis of all available alternatives. A priori bias towards the dominant methodology may reduce decision-making time, but may also reduce the potential of different territories. In different conditions the structure of factors can change significantly and, in particular, the importance of the health care system as a system for reducing and preventing specific «emergency situations» increases significantly. An effective medical development strategy in the territory will significantly reduce the negative effects.

For each of these factors, there are many ways and means to reduce them. In order to develop an adequate management system and improve behaviour, it is important to assess the full range of alternatives.

Institutional analysis of situation and behaviour (identification of major constraints, interdisciplinary nature of the problem, limited rationality and opportunism, routines in decision-making, emerging externalities and institutions) will reveal the main problems and elements of a sustainable development strategy for the territory. Constraints on individual decision-making in the territories allow for a division of methods in terms of the ability to influence the outcome.

Behaviour models are formed by combining the issues of medicine, economics, management, psychology, and biology. The efficiency of the resulting routines depends on the analysis of all alternatives, the total costs and the results associated with them. Failure to explore alternatives creates moral risks for the informed party and the possibility of future extortion.

The experience of 2020 allowed for the development of competencies and actions for the formation and implementation of a strategy of behaviour in the future. At the same time, the distribution and clarification of the causes of mortality and morbidity will make it possible to prioritize the reduction of the cumulative negative effects.

The relationship between conditions and patterns of behaviour in the territory and the health of population requires further research, including statistical data on the impact of the transforming event, which is the outbreak of infectious diseases (in particular COVID-19) in 2020. However, the emergence and detection of psychological disorders as a result of administrative and economic constraints can take a long time.

\section{Conclusion}

A more detailed differentiation of factors is required in order to establish a system of governance and decision-making and, on that basis, the introduction of specific recommendations for a given territory into the routine behaviour of the local population. The formation of an effective strategy for behaviour in the territory (at the individual and administrative level) should involve several stages to be developed through further research. 
Routine behaviour in the territory is shaped by the institutional environment based on the dominant concept and methodology. Different concepts can offer their own set of tools, which implies the need for scientific discussion based on current developments. While methods at different levels of management and stages of impact may be mutually exclusive and largely depend on adherence to a particular concept rather than objective analysis, economic analysis included, at the individual level of management, many of the recommendations are of a compromise nature.

One of the dominant factors contributing to the improvement of public health, particularly in large cities, is the maintenance and strengthening of immunity. The immune system is a complex and research-specific field of interdisciplinary knowledge. The considerable knowledge accumulated in this field makes it possible to address the problems that have previously caused significant damage and loss. Immune regulation is crucial in maintaining the homeostasis of the human body and serves as a natural protective barrier against negative consequences of the aggressive effect of the excessive chemical load onto the urban environment [22]. In this regard, we will consider effective means of increasing immunity in urban environment.

The human immune system is known to consist of an innate and adaptive component, providing the body's humoral and cellular mechanisms of reaction to various infections, toxins and malignant cells. The mechanism of optimal immune responses is based on the ability of cells to produce antibody molecules specific for each antigen. Adequate functioning of the body's immune system requires coordinated work of a single functional complex consisting of three sets of protective mechanisms. One of the non-specific factors is protective and adaptive mechanisms against stress caused by various environmental factors (toxins, cold, hunger, heat, ionizing radiation, etc.) [23].

It is important to note that enhancing the immune system's resilience against external stressors is possible while respecting the basic principles of a healthy lifestyle. The main ones are the absence of bad habits, a rational mode of work and rest, proper fortified nutrition, immunity-boosting regimen, moderate physical activity.

Thus, alcohol abuse negatively affects the production of leukocytes, smoking neutralizes protective cilia in bronchial lungs, and the ingestion of narcotic drugs significantly weakens body's immune system as a whole, making it more vulnerable to infectious agents. On the contrary, regular exposure of the human body to artificially created irritant stressors, which include cold acclimation and physical activity, will greatly enhance and stimulate the immune system, especially in the context of general hypodynamia (lack of motion).

For example, the systematic use of acclimation means - sun, air and water - as natural stimuli, makes the body adaptive and thus increases its resistance to adverse environmental factors. Compliance with the basic rules and principles of acclimation will make it possible to achieve the spiritual and physical balance of homeostasis and will ensure the human immune system fully functioning [24].

Moderate physical activity is an important component that has a positive impact on public health and local immunity in particular. Adequate physical activity during the day, such as morning gymnastics, jogging, walking or swimming in the aerobic range of intensity and short duration, can increase the body's protective mechanisms. However, excessive highintensity loads, «sweat-blood sport» can lead to hormonal imbalance, overtraining, chronic fatigue and, ultimately, long-term immune dysfunction $[25,26]$.

A balanced diet with sufficient vitamins and minerals plays an important role in increasing the body's reserve capacity. Many scientists are prone to the fact that our body does not receive the required amount of necessary micronutrients from food, which must be replenished artificially. For example, recent studies on the effect of vitamin D on the human immune system have shown the need for a high pharmacological dose, regardless of exposure 
to sunlight. The efficiency of vitamin D on viral, bacterial and fungal pathogens in the cells of the human innate immunity was justified, as well as on the weakening of inflammatory processes in the work of acquired immunity [27, 28].

The rational sleep/wake cycle is an important concomitant factor for optimal functioning of the organism and people's immunity. A good night sleep must be at least 7-8 hours, but the modern pace of life, irregular working hours, night shifts adversely affect the quality of sleep. The excessive use of smartphones, tablets, TV sets and other gadgets emitting cold blue light significantly limits the production of melatonin. To ensure healthy sleep it is necessary to refuse food and active exercises a few hours before sleep, go to bed at the same time, create necessary conditions for sleep (air temperature $-18-20^{\circ} \mathrm{C}$, humidity $-50-70 \%$, comfortable sleeping accessories). Healthy sleep is capable of normalizing the body's work, increasing the protective mechanisms of the human immune system [29, 30].

Thus, compliance with simple rules and recommendations in the daily life of a modern urban resident will significantly reduce the impact of aggressive environmental stress factors affecting their health and immunity.

\section{References}

1. P. Symonds, E. Hutchinson, A. Ibbetson, et all., , 697, 134105 (2019) doi.org/10.1016/j.scitotenv.2019.134105

2. M.I. Hussain, European Psychiatry, 41, S572 (2017) doi.org/10.1016/j.eurpsy.2017.01.848

3. H. Anisman, Sh. Hayley, A. Kusnecov, The Immune System and Mental Health. 103139 (2018) doi.org/10.1016/B978-0-12-811351-6.00004-8

4. Ch. Mitsakou, S. Dimitroulopoulou, C. Heaviside, et al., Science of The Total Environment, 658, 1630-1639 (2019) doi.org/10.1016/j.scitotenv.2018.12.130

5. A. Daiber, J. Lelieveld, S. Steven, et al., Oxidative Stress, 489-510 (2020) doi.org/10.1016/B978-0-12-818606-0.00025-0

6. M. Pascal, M. Corso, O. Chanel, et al., Science of The Total Environment, 449, 390400 (2013) doi.org/10.1016/j.scitotenv.2013.01.077

7. N. Manojkumar, B. Srimuruganandam, Science of The Total Environment, 142999 (2020) doi.org/10.1016/j.scitotenv.2020.142999

8. K.E. Altieri, L. Samantha, Science of The Total Environment, 684, 610-620 (2019) doi.org/10.1016/j.scitotenv.2019.05.355

9. H. Dong, M. Xue, Y. Xiao, Y. Liu, Science of The Total Environment, 758, 143688 (2021) doi.org/10.1016/j.scitotenv.2020.143688

10. Ch. Chartasa, J. MacDonald, Science of The Total Environment, 506-507, 409-421 (2015) doi.org/10.1016/j.scitotenv.2014.11.020

11. Ch. Johansson, B. Lövenheim, P. Schantz, et all., Science of The Total Environment, 584-585, 55-63 (2017) doi.org/10.1016/j.scitotenv.2017.01.145

12. D. Sarigiannis, P. Kontoroupis, S. Nikolaki, Science of The Total Environment, 579, 1427-1438 (2017) doi.org/10.1016/j.scitotenv.2016.11.142

13. A. Woodward. J. Baumgartner, K. L.Ebi, et all., Environmental Research, 175, 178185 (2019) doi.org/10.1016/j.envres.2019.05.020

14. D.A. Sarigiannis, Environmental Research, 158, 531-541 (2017)

doi.org/10.1016/j.envres.2017.06.031 
15. N.Likhvar, M.Pascal, K. Markakis,A. Colette, et all., Science of The Total Environment, 514, 439-449 (2015) doi.org/10.1016/j.scitotenv.2015.02.002

16. L.K. Badalyan, V.N. Kurdyukov, A.M. Ovcharenko, Kh.D. Gazgireev, Sustainable Development of Mountain Territories, 11, 2 (40), 249-258 (2019) doi:10.21177/19984502-2019-112-249-258

17. L.Kh. Badalyan, V.N. Kurdyukov, A.M. Ovcharenko, Y.V. Gorshkova, Sustainable development of mountain territories, 10, 2(36), 307-314 (2018) doi:10.21177/19984502-2018-10-2-307-314

18. E. Tkachenko, M. McKee et al. Health Policy and Planning, 15 (2), 164-169 (2000) doi:10.1093/heapol/15.2.164

19. V.N. Kurdjukov, L.Kh. Badalyan, A.M. Ovcharenko, MATEC Web of Conferences 196, 04065 (2019)

20. L.Kh. Badalyan, V.N. Kurdyukov, Y.V. Gorshkova, et all., Sustainable Development of Mountain Territories, 49 (34), 369-378 (2017) 10.21177/1998-4502-2017-9- 4-369-379

21. V.N. Kurdyukov, L.Kh. Badalyan. I.V. Avlasenko, et all., IOP Conf. Series: Earth and Environmental Science, 403 (2019) doi:10.1088/1755-1315/403/1/012080

22. P. Duramad, N.T. Holland, International Journal of Environmental Research and Public Health, 8 (5), 1388-1401 (2011) doi:10.3390/ijerph8051388

23. A.K. Abbas, A.H. Lichtman, S. Pillai, Elsevier Health Sciences (2019)

24. E.G. Arsenadze, Trends in the development of science and education, 62 (2), 50-53 (2020)

25. L.G. Shabalina, K.V. Shultz, Human health, theory and methodology of physical culture and sports, 2 (3), 95-97 (2016)

26. M. Gleeson, Journal of applied physiology, 103(2), 693-699 (2007) doi:10.1152/japplphysiol.00008.2007

27. H.A. Bischoff-Ferrari, A. Shao, B. Dawson-Hughes, et all., Osteoporosis International, 7 (21), 1121-1132 (2010) doi:10.1007/s00198-009-1119-3

28. N. Maruotti, F.P. Cantatore, The Journal of rheumatology, 37 (3), 491-495 (2010) doi:10.3899/jrheum.090797

29. D.P. Cardinali, G.M. Brown, S.R. Pandi-Perumal, Melatonin Research, 4 (1), 206-212 (2021) doi:10.32794/mr11250091

30. L. Besedovsky, T. Lange, J. Born, Pflügers Archiv-European Journal of Physiology, 463 (1), 121-137 (2012). doi:10.1007/s00424-011-1044-0 